\title{
Summary of Research on the Practice Path of Ideological and Political Construction in Courses of Chinese Medicine College
}

\author{
Liuying Chen, Simin Wang* \\ Jiangxi University of Traditional Chinese Medicine, Jiangxi, China \\ ${ }^{*}$ Corresponding author. Email:275348658@qq.com
}

\begin{abstract}
Course Education is a long-term systematic project that runs through the whole process of education and teaching. The development of Course Education construction in Chinese medicine colleges is of practical significance to comprehensively improve students' ideological and moral qualities and cultivate high-quality talents with both ability and political integrity for the cause of Chinese medicine. The article takes "Course Education in Chinese medicine colleges" as the main research object, and summarizes the relevant literature from three aspects: the origin and connotation of Course Education, the value meaning of Course Education construction and the path of practice in TCM Colleges. Based on this, it discusses the shortcomings of existing research and future research prospects, in order to provide experience and enlightenment for similar TCM Colleges and even major universities to Implement Course Education construction.
\end{abstract}

Keywords: Chinese medicine colleges and universities, Course Education, Practice path.

\section{INTRODUCTION}

In the national conference on ideological and political work of colleges and universities, General Secretary Xi Jinping pointed out that the foundation of colleges and universities is to foster virtue through education, "it is vital to make the best of the main channel-classroom teaching, and all courses must go with Course Education, thus forming a synergistic effect"[1]. Therefore, Course Education is a positive response to the instructions of General Secretary $\mathrm{Xi}$ Jinping. By the end of September 2020, the theme of "Course Education" has been searched for a total of 11,516 relevant literature on CNKI. Since the central document clearly put forward the concept of "Course Education" in 2017, the number of articles on this topic has increased year by year. Especially in 2019 and 2020, the number of published papers accounts for more than $80 \%$ of the total number of published papers. It can be seen that with higher attention paid to Course Education by the whole country and society, this course has gradually received more and more attention by scholars. TCM Colleges, as the main force of talent output in the higher education system, not only bear the arduous work of inheriting and developing traditional Chinese medicine as well as serving the people, but also shoulder the significant mission of cultivating excellent talents in traditional Chinese medicine with both ability and political integrity. Therefore, it is of great importance to develop the construction of Course Education in TCM Colleges. By searching keywords "Course Education" combined with "traditional Chinese medicine", a total of 78 relevant papers are found. By reading and teasing the existing literature, a summary is made on the evolution of developing Course Education in TCM Colleges, which is of great practical importance to deepen the cognition of Course Education in TCM Colleges, and promote its practical construction.

\section{THE ORIGIN AND CONNOTATION OF COURSE EDUCATION}

\subsection{The Origin of Course Education}

Now, it's generally accepted that "Course Education" originated from the educational concept of "discipline moral education" first proposed by Shanghai in the progress of promoting the reform of the education of ideology and politics curriculum in 2005. "Shanghai began to design and implement the educational reform 
aimed at promoting the 'disciplinary moral education', decomposing and organically integrating the content of moral education into every curriculum in Shanghai primary and secondary schools, requiring every teacher to assume the main responsibility of classroom moral education, reflecting every moral implication of the course"'[2]. After many stages of practical exploration, Shanghai gradually forms the educational work concept of Course Education. It can be said that the Course Education reforms that Shanghai has promoted in recent years have provided a set of valuable, reference-able and extendable "Shanghai experience" for major universities across the country to Implement Course Education construction. Subsequently, after the launch of the National Conference on Ideological and Political Work in Colleges and Universities, theoretical and practical explorations on the ideological and political construction of college courses have gradually developed and prospered.

\subsection{The Connotation of Course Education}

Regarding the interpretation of the connotation of Course Education, academia has not yet formed a unified opinion, but it can be roughly divided into three aspects: education view, curriculum view and system view.

First, the ultimate goal of Course Education is to educate people. As Gao Deyi and Zong Aidong put forward, the Course Education education is not to open one more class, nor is it to add another activity, but to build morality as the goal, and to infiltrate the the education of ideology and politics of colleges and universities into the entire curriculum teaching and reform process in[3]. Wu Yueqi coincides with this point of view. She believes that Course Education is not only an educational philosophy, but also a way of thinking. Moral education must be adhered to the teaching process of any curriculum in order to implement the fundamental task of establishing morality[4]. Second, Course Education is essentially a curriculum view. Qiu Weiguang believes that Course Education is to require the education of ideology and politics in all courses of colleges and universities. That is, "the curriculum carries ideological and political” and "the ideological and political in the curriculum"[5]. This view is highly consistent with Wang Haiwei and Wang Bocheng's conceptual definition of Course Education[6]. Third, Course Education is a long-term systematic project. From the perspective of system theory, Lu Daokun compares Course Education to a systems engineering, pointing out that the ideological and political construction of professional courses is the core and the most critical part of this project. Only by upholding systems thinking can we effectively promote the implementation of this project[7].
In summary, the Course Education is essentially based on the curriculum as a carrier. By locating the inner point of the education of ideology and politics and professional curriculum, so as to realize value shaping, knowledge transfer and ability training. The organic unity of the whole-course is education environment. At the macro level, the elements of ideology and politics here can be roughly divided into three categories: Devotion to family and country, Personal Self-cultivation and View of Science. Among them, the Devotion to family and country includes identification and adherence to the party and country consciousness, socialist core values, excellent Chinese traditional culture. Personal self-cultivation includes teaching students how to behave in morality, correct overlooks on the world, life and values, and psychology. The View of Science includes teaching students how to do things with studying diligence, seeking truth from facts, critical and creative. Specifically, for TCM Colleges, the elements of ideology and politics mainly include the education of medical ethics, traditional culture, professional responsibility, the correct view on the world, life and values Cultivation, doctor-patient communication, bioethics, benevolence thought, and scientific spirit.

\section{THE VALUE MEANING OF COURSE EDUCATION CONSTRUCTION IN CHINESE MEDICINE COLLEGES}

Regarding the value of the ideological and political construction of courses in TCM colleges, scholars at this stage mainly analyze and discuss from a macro perspective, mainly based on the two main levels of universities and students.

First of all, for TCM Colleges, they not only bears the arduous task of inheriting and innovating traditional Chinese medicine, but also shoulders the grand mission of education. Therefore, the construction of Course Education is vital to practicing the fundamental task of fostering virtue through education and cultivating excellent talents in traditional Chinese medicine with both ability and political integrity. As to the work on traditional Chinese medicine, General Secretary Xi Jinping pointed out that we ought to inherit the essence and try to innovate based on the right track. Strengthening the cultivation of talents in traditional Chinese medicine plays a positive role in inheriting, developing and utilizing the valuable wealth of traditional Chinese medicine, as well as constructing a healthy China. As mentioned by Li Shanshan et al, TCM Colleges need to stick to the orientation of running schools based on socialism with Chinese characteristics, insist on the main task of fostering virtue through education, and actively explore the construction of Course Education that is in line with their education, so that they can cultivate well qualified talents in 
traditional Chinese medicine who are excellent in both character and learning[8].

Secondly, for students, receiving the education of ideology and politics consistent with professional knowledge while learning professional knowledge can help students establish correct moral values and strengthen their confidence in Chinese medicine culture. Referring to the value of similar medical colleges and universities for Course Education construction. Fang Jianhong and others believe that medical ethics education for students in medical colleges can enhance students' comprehensive literacy while highlighting medical characteristics. It can not only help students establish correct ethics and develop good behaviors at the beginning of learning, but also enhance students' sense of social responsibility[9]. Zhou Xiaohang also pointed out that schools should not only allow students to master relevant professional knowledge, but it is more important to cultivate students to establish correct three views[10]. In addition, Jia Ailing and others believe that the effective integration of the education of ideology and politics and teaching content will help enhance students' subjective initiative and enthusiasm in learning, strengthen students' awareness of my country's excellent traditional culture, and enhance their professional identity And national self-confidence[11].

\section{RESEARCH ON THE PRACTICE PATH OF COURSE EDUCATION CONSTRUCTION IN CHINESE MEDICINE COLLEGES AND UNIVERSITIES}

At present, scholars are beginning to pay attention to the research on the practice path of ideological and political construction of courses in TCM Colleges. However, there are few documents that have been found on Chinese Knowledge Network to conduct special research on them. Among the documents that is found, researchers mainly the four paths of textbooks and resources, teaching methods and means, course teachers and teaching evaluation explore the practical paths of Course Education construction in Chinese medicine colleges.

\subsection{Path 1: Strengthen the Construction of Teaching Materials and Resource System}

As an important carrier of Course Education construction, the content and quality of textbooks have an important impact on the achievement of talent cultivation goals in colleges. In order to meet the needs of contemporary talent training, the construction of Course Education related textbooks and resource systems should be strengthened. The key textbooks of the Marxist theoretical research and construction project implemented by the Party Central Committee are a concrete manifestation of strengthening the construction of textbooks under the premise of meeting the requirements of the times and guided by the latest achievements of the Sinicization of Marxism. It has established 139 projects, covering political science, economics, sociology, management and other disciplines. Sun Sun and others proposed that the reform of Chinese medicine textbooks should be based on its talent training rules, and through "second development", the education of ideology and politics should be organically combined, so that Chinese medicine textbooks can adapt to the development of Course Education teaching reform Requirements, thus launching a batch of excellent textbooks[12]. In addition, the integration of Course Education teaching resources in TCM Colleges is also particularly important. Traditional culture, professional responsibilities, and doctor-patient communication all can become important content in the progress of Course Education teaching in TCM Colleges.

\subsection{Path 2: Improve the Teaching Methods and Means of Courses}

Teaching methods and means are important ways and means for the effective implementation of Course Education, so the improvement of teaching methods and means should serve the full realization of the goals of Course Education. Liu Shuming and others believe that it is essential to innovate teaching methods, activate the classroom atmosphere, and enhance the fun of learning[13]. In order to enhance teaching effects, Wang Qingling and others proposed to take experiential teaching methods to better promote the effective implementation of Course Education[14]. In addition, Li Shanshan and others pointed out that based on the professional courses of Chinese medicine colleges and universities, the ideological and political construction of Chinese medicine colleges and universities should conform to the characteristics of various types of Chinese medicine professions. In the course of teaching, modern information technology can be used and problem-oriented teaching methods such as the education of ideology and politics, and situational teaching, constantly improve the affinity and pertinence of the education of ideology and politics[15]. Zhang Lin and others proposed in the study of the teaching reform of the education of ideology and politics in the course of prescriptions. Classroom teaching should use practical cases flexibly, starting from both emotions and knowledge and skills, using storytelling, and cleverly interspersing the content of relevant the education of ideology and politics[16]. 


\subsection{Path 3: Improve Teachers' Ideological and Political Skills and Level}

Teachers play a key role in promoting Course Education construction. Therefore, it is essential to further strengthen teachers' awareness and ability of educating people, reverse their tendency to emphasize knowledge transmission and less value guidance, and ensure that Course Education construction can be implemented. Li Kai and others believe that in order to have a more in-depth understanding and mastery of the content of relevant the education of ideology and politics, they can better play their roles in the course of the education of ideology and politics, training activities and collective learning can be adopted. In this way, the ideological and political literacy of teachers can be improved, and the ideological and political abilities of teachers can be improved[17]. In addition, Chen Ming also proposed that It is essential to Implement teaching training related to Course Education for teachers, and to strengthen the interactive communication and learning between teachers through project establishment and professional seminars, so as to guide teachers to use multiple methods in the teaching process to impart knowledge and lead ideas to students[18]. The author believes that in the progress of promoting the reform of Course Education construction, It is essential to give full play to the main role of professional teachers, and continuously improve teachers' ideological and political skills and levels through various forms of learning exchanges, so as to cultivate students' noble moral sentiment and quality.

\subsection{Path 4: Optimize Teaching Evaluation System and Standards}

Course Education has been a newly proposed course reform measure recent years. It is still in the stage of exploration and development, and its corresponding evaluation system and standards need to be continuously optimized. The teaching evaluation of the implementation effect of Course Education construction is mainly divided into two parts: the evaluation of teachers' teaching and the evaluation of students' learning. Among them, to optimize the evaluation of teachers' teaching, teachers' participation in Course Education construction and teaching effects can be regarded as important content of teaching evaluation. Gao Yan pointed out that the traditional teaching evaluation system and the evaluation system of teachers' professional title appointment in school should be changed. We should focus on cultivating students to possess virtues, focus on process evaluation, and take students' development as the benchmark. In this way, the education of ideology and politics can not only influence the mind, but also regulate behavior. Realize the organic unity of educating people through practice and educating people through teaching[19]. To optimize the evaluation of students' learning, Zou Junbo and others proposed that the corresponding assessment method must be adopted for the students. Ideological and political topics that are compatible with professional knowledge and related to strengthen the subjective initiative of students in their own ideological and political learning[20].

\section{CONCLUSION}

This article clarifies the origin and connotation of Course Education by tracing the research related literature of "Course Education in TCM Colleges" for the last few years, summarizes the value of Course Education construction in TCM Colleges, and also summarizes the research progress of the path of school Course Education construction aims to provide help for the Course Education practice of Chinese medicine colleges and even major universities. In general, at this stage, the research on the ideological and political construction of Chinese medicine colleges and universities has achieved certain results, but there are still some shortcomings and areas for further research, which are briefly described as follows.

First, in TCM Colleges, the research subject in the the construction of Course Education is relatively single, which is not greatly carried forward. According to investigations and statistics, currently, there is no strict requirement on the construction of Course Education in some TCM Colleges. Besides, the publicity is not sufficient enough, and researchers are mostly Course Education teachers. Combined with the ideological and political limitations of teachers in other professional curriculum, the effect of educational resultant force is affected to a certain degree, consequently hindering the effective practice of the construction of Course Education. Therefore, in the practice of boosting Course Education, it is important for these academies to strengthen publicity, practice specific requirements, encourage mutual communication and exchange between specialized course teachers and Course Education teachers, and eventually enhance the construction of Course Education.

Second, the research on the Course Education evaluation system is still relatively scarce, and it is still a blank point. Evaluation guides the development direction of Course Education, and has the functions of diagnosis, guidance, regulation and encouragement. It is very important to construct a Course Education evaluation system. However, from the current research results, whether it is a Chinese medicine college or other universities, the construction of the Course Education evaluation system is still the most confusing and troublesome problem for colleges and teachers in the current Course Education construction. This requires researchers and universities to work together in the future, actively sum up experience, explore general rules, 
and explore and construct a relatively complete Course Education evaluation system to ensure the effective implementation and implementation of Course Education construction and improve teaching quality.

The third is that the research methods of Course Education construction practice paths are more generalized and described less investigation and research. Judging from the existing relevant literature, the current research methods of many scholars on the practice path of Course Education construction are mostly inductive deduction and descriptive analysis, and few scholars use interviews and questionnaire surveys to deal with it. For this reason, in future research, methods such as investigation and research can be used to investigate and analyze the specific conditions in the practice of Course Education construction in TCM Colleges . By formulating detailed research plans to obtain corresponding research data, in order to better Implement Course Education construction for similar Chinese medicine colleges and even major universities, and explore targeted and operable practical paths.

\section{REFERENCES}

[1] Xi Jinping emphasized at the National Conference on Ideological and Political Work in Colleges and Universities: Putting ideological and political work throughout the whole process of education and teaching to create a new situation for the development of higher education in my country [N].

People's Daily, 2016-12-09(1).

[2] Tian Hongfen, Fu Hong. Course Education: the practical path of integrating the teaching of professional courses in colleges and universities into the education of ideology and politics[J]. Future and Development, 2018(4):99-103.

[3] Gao Deyi, Zong Aidong. From ideological and political courses to Course Education: constructing the curriculum system of the education of ideology and politics in colleges and universities from a strategic height[J].China Higher Education, 2017(01):43-46.

[4] Wu Yueqi. On the three focal points of promoting "Course Education" in colleges and universities[J]. School Party Building and Ideological Education, 2018(1):67-69.

[5] Qiu Weiguang. The value meaning and generation path of Course Education [J]. Ideological and theoretical education, 2017(7):10-14.

[6] Wang Haiwei, Wang Bocheng. On the core elements and practical paths of ideological and political courses in colleges and
universities[J].School Party Building and Ideological Education,2018(14):32-34.

[7] Lu Daokun. Several core problems and solutions in the implementation of Course Education--based on the discussion of professional Course Education[J].Ideological and Theoretical Education,2018(3):64-69.

[8] Li Shanshan, Gong Jiyu.Thoughts and explorations on the reform of ideological and political teaching in higher Chinese medicine colleges and universities in the new era[J]. Lishizhen Medicine and Materia Medica, 2019,30(11):2741-2743.

[9] Fang Jianhong, Liu Qunying. The path of good medicine cultivation: integrating medical ethics education into Course Education construction[J].Journal of Nanjing Medical University (Social Science Edition),2018,18(03):238-241.

[10] Zhou Xiaohang. Exploration of the path of classroom ideology and politics in the classroom teaching of medical colleges[J].Science, Education and Literature Collection(First half issue),2020(03):89-90.

[11] Jia Ailing, Dong Jinxiang, Qiu Zhidong. Inquiry into the teaching mode of Chinese pharmacy under the background of ideological and political reforms in Chinese medicine colleges and universities[J].Modern Distance Education of Chinese Medicine,2019,17(08):141-143.

[12] Sun Sun, Huang Guicheng, Wu Qinan, etc.. Research on the construction of Course Education system in higher institutions of Chinese medicine--Taking Nanjing University of Traditional Chinese Medicine as an example[J].Journal of Nanjing University of Chinese Medicine (Social Science Edition),2018,19(04): 262-264.

[13] Liu Shuming, Yan Jufang, Zhang Dingling, etc.. On the Implementation Strategies of Ideological and Political Courses in Colleges and Universities[J].Education Theory and Practice,2019,39(15):44-46.

[14] Wang Qingling, Pan Zongqiu. The Dilemma and Outlet of the Experiential Teaching Method of Ideological and Political Course in Higher Vocational Colleges--Taking the Course of "Ideological and Moral Cultivation and Legal Foundation" as an example[J].Vocational Education Forum,2016(05):74-77 .

[15] Li Shanshan, Gong Jiyu.Thoughts and explorations on the reform of ideological and political teaching 
in higher Chinese medicine colleges and universities in the new era[J]. Lishizhen Medicine and Materia Medica,2019,30(11):2741-2743.

[16] Zhang Lin, Wang Liangbin, Gao Lin, etc.. Exploration of the elements of ideology and politics and implementation methods in the course of prescriptions[J].Education of Chinese Medicine,2020,39(02):80-82.

[17] Li Kai, Tian Lianqi, Li Hongwei and so on. Ideological and political construction and practice of Chinese medicine processing courses in Chinese medicine colleges and universities[J].Journal of Chinese Medicine Management,2019,27(10):15-16.

[18] Chen Ming. Benevolence, benevolence, benevolent man--Thinking and path of ideological and political construction in Chinese medicine colleges and universities[J].Lishizhen Medicine and Materia Medica,2018,29(11):2751-2753.

[19] Gao Yan. Key issues and solutions for Course Education construction[J].China Higher Education,2017(Z3):11-14.

[20] Zou Junbo, Zhang Xiaofei, Guo Dongyan et al. Exploration of the teaching mode of Chinese pharmaceutics under the background of ideological and political reform in Chinese medicine colleges and universities[J].Cultural Innovation Comparative Research,2020,4(06):126-127. 